\title{
DECISION THEORETIC APPROACH TO PLANNING OF ASEISMIC FIRE CISTERNS
}

\author{
By Katsuhiko KURODA*1, Yoshimi NAGAO*2, \\ Kenjiro YASUNO*3, and Yoshiro NAMBA*4
}

\begin{abstract}
In planning and design of an engineering system where risks are potentially included, risk identification and risk estimation are fundamentally important as well as risk evaluation. The present paper focusses on the seismic fire risk potentially included in urban area, and presents a methrd to plan the optimal number of aseismic fire cisterns using Decision Theory.

Decision tree for aseismic fire cisterns is developed and the annual seismic fire risk is formulated based on the decision tree. The objective function for optimal aseismic fire cisterns is presented. Application to Osaka City area shows that the proposed method is rational and useful.
\end{abstract}

\section{INTRODUCTION}

Most Japanse cities and towns have developed along a coast or a river, of which subsoil is usually very weak. Moreover the percentage of wooden houses is relatively high. Therefore once they are attacked by a strong earthquake, serious damages of wooden houses as well as other structures are anticipated including induced fire damage. For this reason, it is strongly desired to improve houses and other structures to be of earthquake proof while fire fighting facilities are equipped as completely as possible. The present fire fighting ability mainely depends on the fire-hydrants of water supply pipeline which are expected to be seriously damaged by a strong earthquake. Therefore lowering of fire fighting ability could not be avoided during the earthquake. However, antiearthquake improvement of existing fire-hydrants will require big amount of money and time and will not be avairable as a tentative measure. Therefore aseismic fire cisterns are considerd as an effective measure. In fact, Tokyo and Osaka have started to construct such aseismic fire cisterns. About fifteen hundreds of aseismic fire cisterns have been constructed in Tokyo. This accounts only $1.4 \%$ of total water supply by existing fire-hydrants including rivers and ponds. In order to obtain useful information on the appropriate number of aseismic fire cisterns, it is necessary to establish a method for planning. Taking this situation into account this paper presents a method for planning of aseismic fire cisterns based on Decion Theory with some numercal examples.

In chapter 2 the planning of aseismic fire cisterns in a given urban area is formulated by Decision Theory.

*1 Member of JSCE Dr. Eng., Associate Prof. of Kyoto Univ. (Sakyo-ku, Kyoto 606)

*2 Member of JSCE Dr. Eng., Prof. of Kyoto Univ. (Sakyo-ku, Kyoto 606)

*3 Member of JSCE Dr. Eng., Prof. of Kinki Univ. (Kure-shi, Hiroshima 737-01)

*4 Member of JSCE Dr. Eng., Assistant Prof. of Kinki Univ. (Kure-shi, Hiroshima 737-01) 
The estimation procedure of annual fire risk level due to earthquake is discussed in chapter 3 .

Chapter 4 presents some numerical examples in case of Osaka. Concluding remarks and issues remained in future are discussed in chapter 5.

\section{FORMULATION OF PLANNING OF ASEISMIC FIRE CISTERNS}

\section{(1) Decision Tree Analysis}

The analysis of undesirable events for human socienty such as natural hazards, accidents, pollutions and so forth and the analysis of their countermeasures are usually called as "Risk Assessment". According to Kates (1976), risk assessment implies two aspects ; one is Risk Determination, and the other is Risk Evalution.

Risk Determination involves two steps : risk identification and risk estimation. Risk identification is the step where potential risks in a concerned system are identified. This means the analysis of what undesirable events and induced consequences potetially exist in the system and what their causative events are. Risk estimation is the step where probabilities of occurrences of the causative events and their induced consequences are estimated and the consequences are valued.

Risk Evaluation implies to find risk reduction and/or risk averse (if avoidable) actions and to evaluate the actions.

Risk focussed in the present paper is associated with the fire of houses induced by earthquakes, and the risk reduction action is equipment of aseismic fire cisterns. The problem to be solved is to determine an appropriate number of the aseismic fire cisterns in a unit area of a city. This problem can be well defined in the decision tree form as shown in Fig. 1.

The occurrence of losses due to seismic fires is uncertain for the planner. Therefore, choice of the best from alternative actions (number of aseismic fire cisterns) is the decision under uncertainty. This is the reason why the problem can be formulated by Decision Theory.

In formulating the problem, the introduced premises and assumptions are as follows:

1) Land use of the concerned city is given. This is denoted by $L$ in Fig.1.

2) The number of houses in unit zone of the city is given. The area of this unit zone is constant.

3) The total area of floors of inflammable houses in the zone is $G$ in square meters.

4) Fire spreads only through inflammable houses which are assumed as only wooden houses in the present paper.

5) Total area of floors of burnt out houses is estimated by the fire-spreading model developed by the authors, which will be explained in the successive chapter.

6) Fire-hydrants equipped with water supply pipelines are assummed to be not available after the

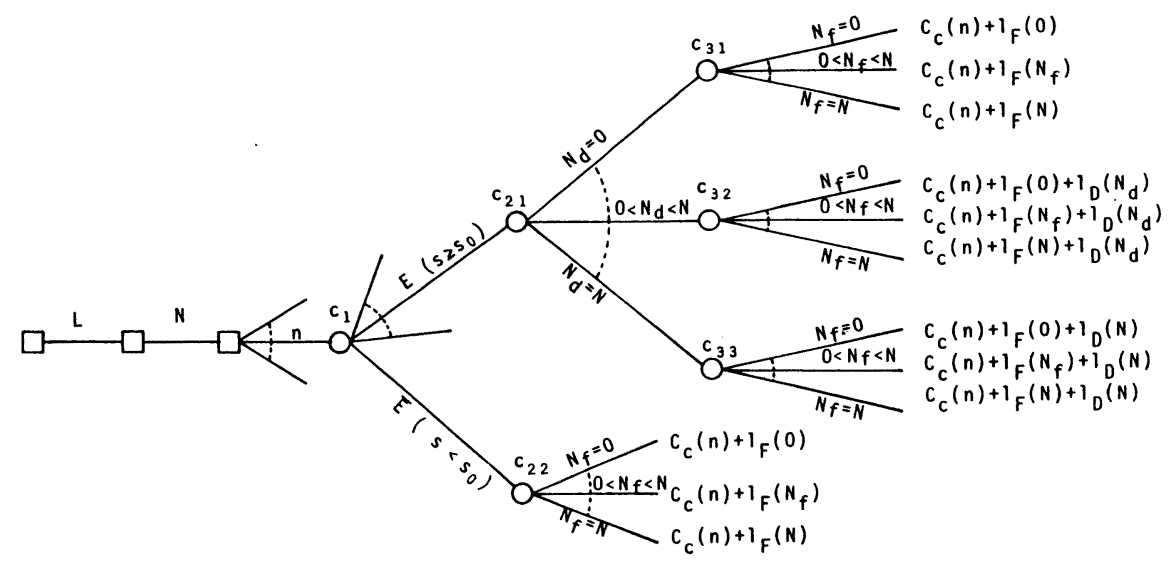

Fig. 1 Decision tree. 
shock of an earthquake with damaging intensity.

7) Equal number of aseismic fire cisterns, $n$, is planned in each of unit zones of constant area.

8) Fatality is not considered and consequence of an action are evaluated in monetary term, that is, induced economical loss. Of course inhabitants should be evacuated by making appropreate refuge plan.

9) The planner is assumed to be an expected monetary valuer.

10) Fire engines and fire men are assumed to be available after a strong earthquake.

Concerning with the assumption 6), the reason why this is assumed is as follows; The availability of fire-hydrant after shock may depend on the intensity of the earthquake at the site. However it is quite difficult to estimate the avairability of the fire-hydrants for any earthquake intensity. But, when earthquakes inducing structural damages are considerd, the reliability of existing pipelines may be quite low. For example, Matsuo et al. (1979) show the failure probability of joint of pipes and a pipe itseif is about 0.1 . This means the failure probability of the pipeline system with many joints and pipes is quite high under the assumption that the failures of each joint and pipe are statistically independent. Therefore the assumption introduced here could be acceptable at present. It should be noticed that this assumption means no available water supply for fire fighting except natural water supply such as rivers and ponds after an earthquake shock.

Under these premises and assumptions the problem can be expressed by the decision tree shown in Fig. 1, where symbols of square and circle denote the decision fork and chance fork, respectively.

Since the land use $L$ and the number of houses $N$ in a certain unit zone in the city are assumed to be given in the present paper, the decision is associated only with the number $n$ of aseismic fire cisterns in the zone. At the chance fork $c_{1}$, an earthquake $E(s)$ of intensity $s$ is given as one of possible events. As discussed later, the intensity $s$ of an earthquake at a site is defined by the response spectral accelertion given by Scawthorn et al. (1982). $s_{0}$ denotes the minimum level of the response spectral acceleration which induces structural damages. Therefore, all earthquakes whose intensities are $s<s_{0}$ can be included in the event of no earthquake occurrence denoted by $\bar{E}\left(s<s_{0}\right)$. Hereafter, $\bar{E}\left(s<s_{0}\right)$ is called as "usual state". At the chance fork $c_{1}$, if no earthquake occurs, it leads to the chance fork $c_{22}$ where number of fire break-out houses $N_{f}$ is considered as possible outcomes in the usual state. The consequence of each outcome is expressed by the loss function $l_{\bar{E}}\left(N_{f}, n\right)$. This loss fuaction is given by

$$
l_{\bar{E}}\left(N_{f}, n\right)=C_{c}(n)+l_{F}^{*}\left(N_{f}\right) \quad 0 \leq N_{f} \leq N
$$

where $l_{F}^{*}\left(N_{f}\right)$ is the total monetary loss induced by $N_{f}$ break-out fires under the usual state and $C_{c}(n)$ is the initial construction cost of $\mathbf{n}$ aseismic fire cisterns.

Now at the chance fork $c_{1}$, if an earthquake $E\left(s>s_{0}\right)$ of intensity $s$ happens to occur, it leads to the chance fork $c_{21}$ where the outcome may change from no damage of houses denoted by $N_{d}=0$ to collapse of all houses denoted by $N_{d}=N$. At the chance fork $c_{21}$, if $N_{d}=0$ happens to occur, it leads to the chance forks $c_{31}$ which is given by the same tree as $c_{22}$. On the other hand, if $N_{d}$ houses collapse, it yields to the chance fork $c_{32}$ of which outcome may change from no fire break-out denoted by $N_{f}=0$ to fire break-out of all houses of the unit zone denoted by $N_{f}=N$. Again the induced consequence of each outcome can be expressed by the loss function $l_{E}\left(N_{f}, N_{d}, n\right)$. This is given by

$$
l_{E}\left(N_{f}, N_{d}, n\right)=C_{c}(n)+l_{F}\left(N_{f}, n\right)+l_{D}\left(N_{d}\right) \quad 0 \leq N_{f}, N_{d} \leq N
$$

where $l_{E}\left(N_{f}, n\right)$ is the total loss in monetary term due to $N_{f}$ break-out fires, and $l_{D}\left(N_{d}\right)$ is the loss of $N_{d}$ collapsed houses.

\section{(2) Probability Assignment and Expected Loss}

It should be noticed that each branch of a chance fork has its own probability of occurrence. In assigning the probability to each branch, following notations are introduced :

$\phi_{E}(s)$ : probability density function of annual occurrence of earthquakes of response spectral acceleration $s$. (hereafter the present paper often uses the term of earthquake $s$.) 
$p_{F}\left(N_{f} \mid \bar{E}\right)$ : conditional probability density funtion that $N_{f}$ houses catch fire under the usual state.

$p_{D}\left(N_{d} \mid s\right)$ : conditional probability density funtion that $N_{d}$ houses collapse when earthquake $\mathrm{s}$ occurs.

$p_{\bar{E}}(\bar{E})$ : probability of non earthquake occurrence per year.

$p_{F}\left(N_{f} \mid N_{d}, s\right)$ : conditional probability density function that $N_{f}$ houses catch fire when $N_{d}$ houses are collapsed due to earthquake $s$.

Using these notations the probabilities are assigned at each branch of chance forks as shown in Fig. 2, where the consequences are also given at the tip of each branch.

If the planner is an expected monetary valuer (EMVer), the optimal action is what minimizes the expected loss. In more general approaches a utility function shouid be introduced in stead of montary value. However, public agency is considerd to have a linear unility function for monetary value (Ang and Tang, 1984). In such a case the analytical results do not depend on whether a utility function is introduced or not. Therefore in the present paper maxi-EMV criterion is used.

Referring to Fig. 2, EMVs at the chance forks $c_{31}, c_{32}$, and $c_{33}$ are calculated by

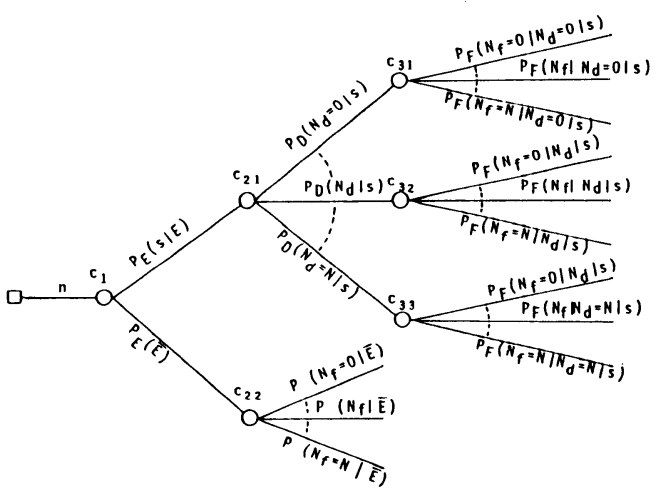

Fig. 2 Probability of each event.

$$
\begin{aligned}
E M V_{(j)}= & \sum_{N_{f=0}}^{N}\left[C_{c}(n)+l_{F}\left(N_{f}, n\right)+l_{D}\left(N_{d}\right)\right] \times p_{F}\left(N_{f} \mid N_{d}, s\right) \\
& (j=31,32,33) \ldots \ldots \ldots \ldots \ldots \ldots \ldots \ldots \ldots \ldots \ldots \ldots \ldots \ldots \ldots \ldots
\end{aligned}
$$

where $j$ denotes the name of the chance fork $c_{j}$.

Thus the $E M V$ at the chance fork, $c_{21}$, is given by

$$
\begin{aligned}
E M V_{21}= & \sum_{N_{d}=0}^{N} \sum_{N_{f=0}}^{N}\left[C_{c}(n)+l_{F}\left(N_{f}, n\right)+l_{D}\left(N_{d}\right)\right] \\
& \times p_{F}\left(N_{f} \mid N_{d}, s\right) p_{D}\left(N_{d} \mid s\right) \ldots \ldots \ldots \ldots \ldots
\end{aligned}
$$

In Eq. $(4)$, the loss $l_{F}\left(N_{f}, n\right)$ menas the total loss induced by $N_{f}$ break-out fires. This includes the losses of all properties due to fire-spreading from $N_{f}$ fires.

Fire-spreading can be reduced by fire-fighting activities which depend on the number of aseismic fire cisterns, because they are available for water supply even after an earthquake shock. Therefore, the loss $l_{F}$ is given as a function of $N_{f}$ and $n$.

Now $l_{F}\left(N_{f}, n\right)$ is assumed to have a form of

$l_{F}\left(N_{f}, n\right)=f(n) N_{f}$

in which $f(n)$ is a function of $\mathrm{n}$ and independent of $N_{f}$. This will be shown in the subsequent chapter.

Applying Eq. (5) to Eq. (4), $E M V_{21}$ can be simplified as

$$
E M V_{21}=C_{c}(n)+\sum_{N_{d}=0}^{N}\left[f(n) \bar{N}_{f}\left(N_{d}\right)+l_{D}\left(N_{d}\right)\right] \times p_{D}\left(N_{d} \mid s\right)
$$

where $\bar{N}_{f}\left(N_{d}\right)$ is the expected number of break-out fires under given condition that $N_{d}$ houses are collapsed due to earthquake $s$, and it is given by

$$
\bar{N}_{f}\left(N_{d}\right)=\sum_{N_{f}=0}^{N} N_{f} p_{F}\left(N_{f} \mid N_{d}, s\right)
$$

Similarly the $E M V$ at the chance fork, $c_{22}$, is calculated as

$$
E M V_{22}=C_{c}(n)+\sum_{N_{f}=0}^{N} l_{F}^{*}\left(N_{f}\right) p\left(N_{f} \mid \bar{E}\right)
$$

From Eqs. (6) and (8), the $E M V_{1}$ at the chance fork, $c_{1}$, is given by

$$
E M V_{1}=C_{c}(n)+\int_{s>s_{0}} \sum_{N_{d}=0}^{N}\left[f(n) \bar{N}_{f}\left(N_{d}\right)+l_{D}\left(N_{d}\right)\right] \times p_{D}\left(N_{d} \mid s\right) \phi_{E}(s) d s+\sum_{N_{f}=0}^{N} l_{F}^{*}\left(N_{f}\right) p_{F}\left(N_{f} \mid \bar{E}\right) \times p_{\bar{E}}(\bar{E})
$$

In Eq. (9), $l_{D}\left(N_{d}\right)$ and $l_{F}\left(N_{f}\right)$ are independent of $n$, and thus it can be rewritten as 


$$
E M V_{1}=C_{c}(n)+R_{0}(n)+C_{0}
$$

where $R_{0}(n)$ is the annual seismic fire risk of the concerned zone of a city and is given by

$$
R_{0}(n)=\int_{s>s_{0}}\left[\sum_{N_{d}=0}^{N} f(n) \bar{N}_{f}\left(N_{d}\right) p_{D}\left(N_{d} \mid s\right)\right] \times \phi_{E}(s) d s
$$

and

$$
\begin{aligned}
C_{0}= & \int_{s>s_{0}}\left[\sum_{N_{d}=0}^{N} l_{D}\left(N_{d}\right) p_{D}\left(N_{d} \mid s\right)\right] \phi_{E}(s) d s \\
& +\sum_{N_{f}=0}^{N} l_{F}\left(N_{f}\right) p_{F}\left(N_{f} \mid \bar{E}\right) p_{\bar{E}}(\bar{E}) \ldots \ldots \ldots \ldots
\end{aligned}
$$

According to Mizuno et al. (1976), $\bar{N}_{f}\left(N_{d}\right)$ in Eq. (11) is statistically analyzed as

$$
\bar{N}_{f}\left(N_{d}\right)=\gamma_{1} N\left(\frac{N_{d}}{N}\right)^{\gamma_{2}}
$$

in which $\gamma_{1}$ and $\gamma_{2}$ are the regression coefficients whose values are given in Table 1.

Applying Eq. (13) to Eq. (11), and using second order approximation of Taylor's Series Expansion, Eq. (11) yields

$$
R_{0}(n)=\int_{s>s_{0}} f(n) \gamma_{1} N\left[\left(\frac{\bar{N}_{d}(s)}{N}\right)^{\gamma_{2}}+\frac{1}{2} \gamma_{2}\left(\gamma_{2}-1\right)\left(\frac{\bar{N}_{d}(s)}{N}\right)^{\gamma_{2}-2} \sigma_{N_{d}}^{2}\right] \phi_{E}(s) d s
$$

where $\bar{N}_{d}(s)$ is the expected number of houses collapsed due to earthquake $s$, and given by

$$
\bar{N}_{d}(s)=\sum_{N_{d}=0}^{N} N_{d} p_{D}\left(N_{d} \mid s\right)
$$

In Eq. (14) the second term is negligibly smal comparing with the first term. This can be easily ascertaind by numercal computations. Table 2 shows the computed results of these two terms for verious cases. As this consequence, Eq. (14) can be approximated as

$$
R_{0}(n)=\int_{s>s_{0}} f(n) \gamma_{1} N\left[\frac{\bar{N}_{d}(s)}{N}\right]^{\gamma_{2}} \phi_{E}(s) d s
$$

Further, $\bar{N}_{d}(s)$ in Eq. (16) is given by Scawthorn et al. (1982) as

$$
\bar{N}_{d}(s)=\lambda_{1} s^{\lambda_{2}}
$$

where $\lambda_{1}$ and $\lambda_{2}$ are regression coefficients whose values are also given in Table 1.

Substituting Eq. (17) into Eq. (16), $R_{0}(n)$ is rewritten as

$$
\begin{aligned}
& R_{0}(n)=\int_{s>s_{0}} \tilde{l}_{F S}\left(n, N_{f}\right) \phi_{E}(s) d s \\
& \tilde{l}_{F S}\left(n, N_{f}\right)=f(n) \bar{N}_{f}(s) \ldots \ldots \ldots \ldots
\end{aligned}
$$

where $\bar{N}_{f}(s)$ is the expected number of houses which catch fire after an earthquake $s$, and given by

$$
\bar{N}_{f}(s)=\gamma_{1} N^{1-\gamma_{2}}\left(\lambda_{1} s^{\lambda_{2}}\right)^{\gamma_{2}}
$$

\section{(2) Objective Function}

Since the annual seismic risk $R_{0}(n)$ is expected every year for the period $T$ during of which the aseismic fhre cisterns keep its function, the total seismic risk over $T$ years should be considerd. The present value of this total seismic risk $R_{T}(n)$ is given by

$$
R_{T}(n)=\sum_{j=1}^{T} \frac{R_{0}(n)}{(1+r)^{j}}=R_{0}(n) \frac{(1+r)^{T}-1}{r(1+r)^{T}}
$$

where $r$ is the social discount rate. It should be further noticed that the construction $\operatorname{cost} C_{c}(n)$ and the seismic fire risk $R_{T}(n)$ depend on the conditions of a zone $\mathrm{i}$ of a city.

Expressing this in an explicit manner, the following new notations are introduced: 
$C_{c}^{i}(n)$ : construction cost of aseimic fire cisterns in zone $i$.

$R_{T}^{i}(n)$ : total seismic fire risk of zone $i$.

$C_{0}^{i}$ : constant given by Eq. (12).

Now the total expected loss over $m$ zones and $T$ years is given by

$E M V(n, T)=\sum_{i=1}^{m}\left[C_{c}^{i}(n)+R_{T}^{i}(n)+C_{0}^{i}\right]$

As already mentioned, the constants $C_{0}^{i}$ is independent of $n$. Then it can be omitted from objective function. Therefore the objective function for planning of aseismic fire cisterns is given by

$$
\min _{n} \cdot\left[\sum_{i=1}^{m}\left\{C_{c}^{i}(n)+R_{T}^{i}(n)\right\}\right]
$$

\section{ESTIMATION OF ANNUAL SEISMIC FIRE RISK}

As conducted in Eq. (18), $R_{0}(n)$ is a function of $f(n)$ and $\bar{N}_{f}(s) . f(n)$ is the economical loss due to burnt out houses and other properties induced by fire-spreading from a fire, and $N_{f}(s)$ is the expected number of break-out fires after an earthquake $s$. Therefore, in order to estimate $f(n)$, fire-spreading model is needed.

Empirical formulas of fire spreading speed have been proposed by Suzuki and Kinbara (1940), the Study Team of Fire Prevention of Tokyo (1942), Tosabayasi (1947), Hamada (1951), Hisida (1954), Horiuti (1961) and Yasuno (1968). Further, Fujita (1975) and Sakai (1983) developed simulation models of the fire-spreading based on Hamada's formula. These formulas and simulation models have been developed on the basis of the fire data before 1945. Therefore, it is doutful to apply these to modern urban area of which houses and buildings have extremely changed since 1945. In fact, it is pointed out by Sasaki (1976) and Yamashita (1977) that Hamada's and Horiuchi's formulas tend to overestimate the fire-spreading speed. Thus in the present paper, a model developed recently by Yasuno et al (1982 a, 1982 b, 1982 c, 1983) is used.

This model is based on recent real fire data. Then it is more applicable to fires of modern houses (details should be referred to Namba, 1984).

The model is given by

$$
A(t, v)=\frac{G+e \cdot p}{1+\exp [-a(t-c)]}-\frac{G+e \cdot p}{1+\exp (a \cdot c)}
$$

where $A(t, v)$ is the area of burnt out floors of houses in square meters at the time $t$ (in minute) after a fire breaks out under wind velocity $v(\mathrm{~m} / \mathrm{s})$ without any fire fighting activity, $G$ is the total area in square meters of floors of inflammable houses in a zone. Determing the value of $G$ needs somewhat technical considesations. However, its explanation is omitted here because of lack of space of the present paper. Details should be referred to Yasuno et al. (1983) or Namba (1984), $a, c, e$ and $p$ are given by

$$
\begin{aligned}
& a=\left(0.175+0.0245 v^{1.62}\right)\left(\frac{175}{G}\right)^{0.582 \exp (-0.146 v)} \\
& c=\left[\ln \left(0.980 a^{1.40} G\right)\right] / a \\
& p=G /[1+\exp (a \cdot c)] \\
& e=\left(1.39-2.82 \times 10^{-4} G\right) \exp \left[\left(5.16 \times 10^{-2}+3.29 \times 10^{-4} G-2.18 \times 10^{-7} G\right) v\right]
\end{aligned}
$$

When fire-fighting activities begin at the time $t_{0}$ (in minutes) after a fire breaks out, the total area of burnt out floors after $\tau$ minutes of fire-fighting from $t_{0}$ is approximated by

$$
\begin{aligned}
& A\left(t_{0}+\tau, v\right)=\sum_{j=1}^{n^{\prime}}\left[1+k_{0}(j \cdot \Delta \tau)\right] A\left(t_{0}, v\right) \quad\left(\Delta t=\tau / n^{\prime}\right) \cdots \\
& k_{0}(\tau)=\frac{q_{0}\left[A\left(t_{0}+\tau-\Delta \tau\right)-A\left(t_{0}+\tau-2 \Delta \tau\right)\right]}{Q\left(\tau-\frac{\Delta \tau}{2}\right)-q_{0}\left[A\left(t_{0}+\tau-\Delta \tau\right)-A\left(t_{0}+\tau-2 \Delta \tau\right)\right]}
\end{aligned}
$$


where $q_{0}$ is the water volume per unit time for extinguishment of unit area of floor, and $Q(\tau)$ is the total water volume per unit time for fire-fighting. $Q(\tau)$ used for fire-flghting depends on the number of mobilized fire-engines and the capacity of aseismic fire cisterns. According to the Japanese Association of Fire Science and Engineering (1950), $Q(\tau)$ is approximately given by

$$
Q(\tau)=\alpha \tau^{\beta}
$$

in which $\alpha$ and $\beta$ are the coefficients determind by fire-fighting level. Fire-fighting level is defined by the number of mobilized fhre engines. Fire Defence Division of Fire-Defence Agency of Japan (1978) reports that the water volume necessary for fire-fighting a usual fire is about $40 \mathrm{~m}^{3}$ per a fire engine, and that the available area of a fire-engine to fight a fire is about $62000 \mathrm{~m}^{2}$, which is almost equivalent to the area of 250 meters aquare. Therefore, level 1 of fire fighting means one fire engine and $40 \mathrm{~m}^{3}$ water supply per 250 meters square, level 2 implies two fire engines and $80 \mathrm{~m}^{3}$ water supply per 250 meters aquare, and so forth. According to these standards defining $n$ as the number of aseismic fire cisterns of $100 \mathrm{~m}^{3}$ capacity per 250

Table 3 Fire fighting level.

\begin{tabular}{|c|c|c|c|c|c|c|}
\hline \multicolumn{2}{|c|}{ Fire fighting level } & level 1 & level 2 & level 3 & level 4 & level 5 \\
\hline \multirow{2}{*}{$\begin{array}{l}\text { Number of } \\
\text { assicisic fire } \\
\text { cisteris n } \\
\end{array}$} & $40 \mathrm{~m}^{\mathrm{m}}$ & 4 & 8 & 12 & 16 & 20 \\
\hline & $100 \mathrm{~m}^{2}$ & 2 & 4 & 6 & 8 & 10 \\
\hline \multirow{2}{*}{$\begin{array}{l}\text { Coeffcients } \\
\text { of fire-flow } \\
Q\end{array}$} & $\alpha$ & 0.451 & 0.648 & 0.845 & 0.9435 & 1.042 \\
\hline & $\beta$ & 0.258 & 0.3175 & 0.437 & 0.482 & 0.527 \\
\hline
\end{tabular}

meters square, the coefficients $\alpha$ and $\beta$ are given in

Table 3 . In this table, the cisterns of $100 \mathrm{~m}^{3}$ capacity are evaluated as approximately two cisterns of $40 \mathrm{~m}^{3}$ capacity. In the meanwhile, the time $t_{0}$ in Eq. (25) and (26) depends on the damaged level of access roads after earthquake $s$. This is eastimated by Scawthorn et al. (1982) as

$$
t_{0}=60(0.15+0.85 s)
$$

Applying Eqs. (27) and (28) to Eq. (26), the total area of burnt out floors with fire-fighting activities can be redenoted as $A\left(t_{0}(s)+\tau, v, n\right)$. Using this notation, the time when the spreading fires are diminished is given by the solution of the equation

$$
A\left(t_{0}(s)+\tau, v, n\right)=A\left(t_{0}(s)+\tau-\Delta \tau, v, n\right)
$$

The solution of Eq. (29) is the function of $s, v$ and $n$. Denoting $\tau^{*}$ as this solution, it is expreassed as $\tau^{*}$ $=\tau^{*}\left(t_{0}(s), v, n\right)$. Therefore the time $t^{*}$ when the spreading fire is diminished is given by $t^{*}=t_{0}(s)+$ $\tau^{*}$. Thus, the total area of burnt-out floors up to this time is given as

$$
A\left(t^{*}, n, v\right)=\sum_{j=1}^{m}\left[1+k_{0}\left(j \Delta \tau^{*}\right)\right] A\left(t_{0}, v\right) \quad\left(\Delta \tau^{*}=\tau^{*} / n^{\prime}\right)
$$

When the average economical loss per square meqers of floors is defined by $c_{f}$, the total economical loss, $l(n, v, s)$ is given by

$l(n, v, s)=c_{f} \cdot A\left(t^{*}, n, v\right)$

Since Eq. (31) gives the economical loss induced by a fire, the total economical loss, $l\left(n, \bar{N}_{f}(s), v\right)$ due to $\bar{N}_{f}(s)$ break-out fires is

$$
l\left(n, \bar{N}_{f}(s), v\right)=c_{f} \cdot A\left(t^{*}, n, v\right) \bar{N}_{f}(s)
$$

This economical loss changes as the wind velocity $v$. Thus, the expected loss $l\left(n, N_{f}(s)\right)$ is defined as

$$
l\left(n, \bar{N}_{f}(s)\right)=\int_{v} c_{f} \cdot A\left(t^{*}, n, v\right) \bar{N}_{f}(s) \phi_{v}(v) d v
$$

in which $\phi_{v}(v)$ is the probability density function of $v$.

It should be noticed that Eq. (33) is equivalent to Eq. (18·b). Then,

$$
f(n) \bar{N}_{f}(s)=\int_{v} c_{f} \cdot A\left(t^{*}, n, v\right) \bar{N}_{f}(s) \phi_{v}(v) d v
$$

or

$$
\begin{aligned}
& f(n)=\int_{v} c_{f} \cdot A\left(t^{*}, n, v\right) \phi_{v}(v) d v \ldots \ldots \ldots \ldots \ldots \ldots \ldots \ldots \ldots \ldots \ldots \ldots \ldots \\
& \text { Substituting Eq. (36) into Eq. }(18 \cdot \mathrm{a}), \text { the annua } \\
& R_{0}(n)=\int_{s>s_{0}}\left[\int_{v} c_{f} \cdot A\left(t^{*}, n, v\right) \phi_{v}(v) d v\right] \bar{N}_{f}(s) \phi_{E}(s) d s
\end{aligned}
$$

Substituting Eq. (36) into Eq. (18・a), the annual seismic fire risk $R_{0}(n)$ is rewritten as 


\section{APPLICATION TO OSAKA CITY}

\section{(1) Data Used For Computation of Fire- spreading Model}

Osaka city area is devided into 671 zone squared by $500 \mathrm{~m} \times 500 \mathrm{~m}$. In zoning, zones whose land area is less than $50 \%$ are omitted because in such zones natural water supply by rivers and ponds are available even after a strong earthquake. Thus the total area of 671 zones accounts about $86 \%$ of Osaka city area. All the data of each zone necessary for computation of the fire-spreading model discussed in the previous chapter are based on the statistics stocked at Comprehensive Planning Bureau of Osaka City (1976), and Fire Department of Osaka City (1981). Details of these data can not be presented here, Then the averaged data over 671 zones are shown in Table 4.

The probability density functions of wind velocity and response spectral acceleration are employed from the works by Scawthorn et al. (1982), that is,

$$
\begin{aligned}
\phi_{v}(v)= & 1.0474 \exp [-1.0474(v-3.2067)] \\
& \times \exp [-\exp (-1.0474(v-3.2067))]
\end{aligned}
$$

\begin{tabular}{|c|c|c|}
\hline Factors of data & Average & S tandard dev. \\
\hline 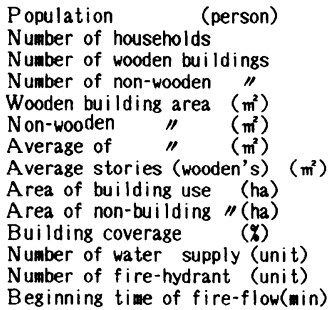 & 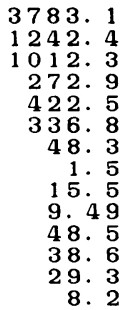 & 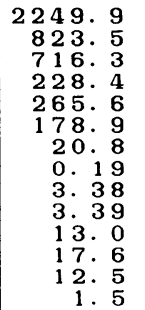 \\
\hline
\end{tabular}

Table 4 The statistics of basic date of Osaka.

Table 5 The values of $\delta$.

\begin{tabular}{c|r|r|r|c}
\hline Soil type & $\delta_{1}$ & $\delta_{2}$ & $\delta_{3}$ & $\delta_{4}$ \\
\hline Soft & 0.625 & 26.38 & 84.7 & 123.4 \\
\hline Interm. & 0.576 & 34.47 & 143.04 & 284.53 \\
\hline Hard & 1.0875 & 73.88 & 539.1 & 1450.0 \\
\hline
\end{tabular}

Table 6 Optimal number of aseismic fire cisterns for

\begin{tabular}{|c|c|c|c|c|c|c|c|c|c|c|}
\hline \multirow{2}{*}{\multicolumn{2}{|c|}{ 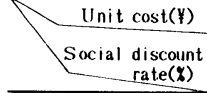 }} & \multicolumn{3}{|c|}{100000} & \multicolumn{3}{|c|}{200000} & \multicolumn{3}{|c|}{300000} \\
\hline & & 6 & 7 & 8 & 6 & 7 & 8 & 6 & 7 & 8 \\
\hline \multirow{2}{*}{$\begin{array}{l}\text { Optimal } \\
\text { fire } \\
\text { cisterns }\end{array}$} & per $\mathrm{km}^{2}$ & 14.8 & 14.4 & 14.4 & 15.6 & 15.6 & 15.2 & 15.6 & 15.6 & 15.6 \\
\hline & per a zone & 3.7 & 3.6 & 3.6 & 3.9 & 3.9 & 3.8 & 3.9 & 3.9 & 3.9 \\
\hline \multicolumn{2}{|c|}{ Total risk $\left(\times 10^{8}\right.$ yen $)$} & 297 & 292 & 288 & 342 & 335 & 328 & 382 & 372 & 363 \\
\hline
\end{tabular}
various cases.

and

$$
\phi_{E}(s)=-\left(-\delta_{2}+2 \delta_{3} s-3 \delta_{4} s^{2}\right) \times \exp \left(\delta_{1}-\delta_{2} s+\delta_{3} s^{2}-\delta_{4} s^{3}\right) \times \exp \left[-\exp \left(\delta_{1}-\delta_{2} s+\delta_{3} s^{2}-\delta_{4} s^{3}\right)\right]
$$

in which parameters $\delta_{1}, \delta_{2}, \delta_{3}, \delta_{4}$ depend on soil condition at a site. Their values are given in Table 5 .

\section{( 2 ) Computed Results and Discussions}

The value of parameters used for computation of $R_{T}(n)$ are listed in Table 6 . The construction cost of aseismic fire cistern of $100 \mathrm{~m}^{3}$ capacity is assumed as ten million yen. This is assumed based on the information collected by hearing at the Fire Departments of Osaka City and Tokyo City. The computation process of annual seismic fire risk is presented in Fig. 3.

One of the example of computed results is presented in Fig. 4. As can be seen from this figure, the annual seismic fire risk is rapidly reduced as the number of aseismic fire cisterns increases from two to four. This reason is considered as follows : In the present case study 500 meters square is considerd as the unit area, then two aseismic fire cisterns of $100 \mathrm{~m}^{3}$ capacity means $50 \mathrm{~m}^{3}$ water supply per 250 meters square, which is not enough for more than two fire-engines as already mentioned. As this consequence the spreaded fires in this zone can not be extinguished. However if four aseismic fire cisterns are planned in 500 meters square, $100 \mathrm{~m}^{3}$ water supply is available for fire-fighting in 250 meters square. This may be enough for extiguishing the spreaded fires in the concernd zone. Of course the efficiency of fire risk reduction depends on the land use, number of inflammble houses, soil conditions at the site and also on the strength of houses. Therefore if these conditions are changed the fire risk reduction efficiency will be changed.

The optimal number of aseismic fire cisterns to be planned in 500 meters square is shown in Table 6 for various values of social discount ratio and monetary value of unit area of burnt out floor. From this table followings are concluded: 


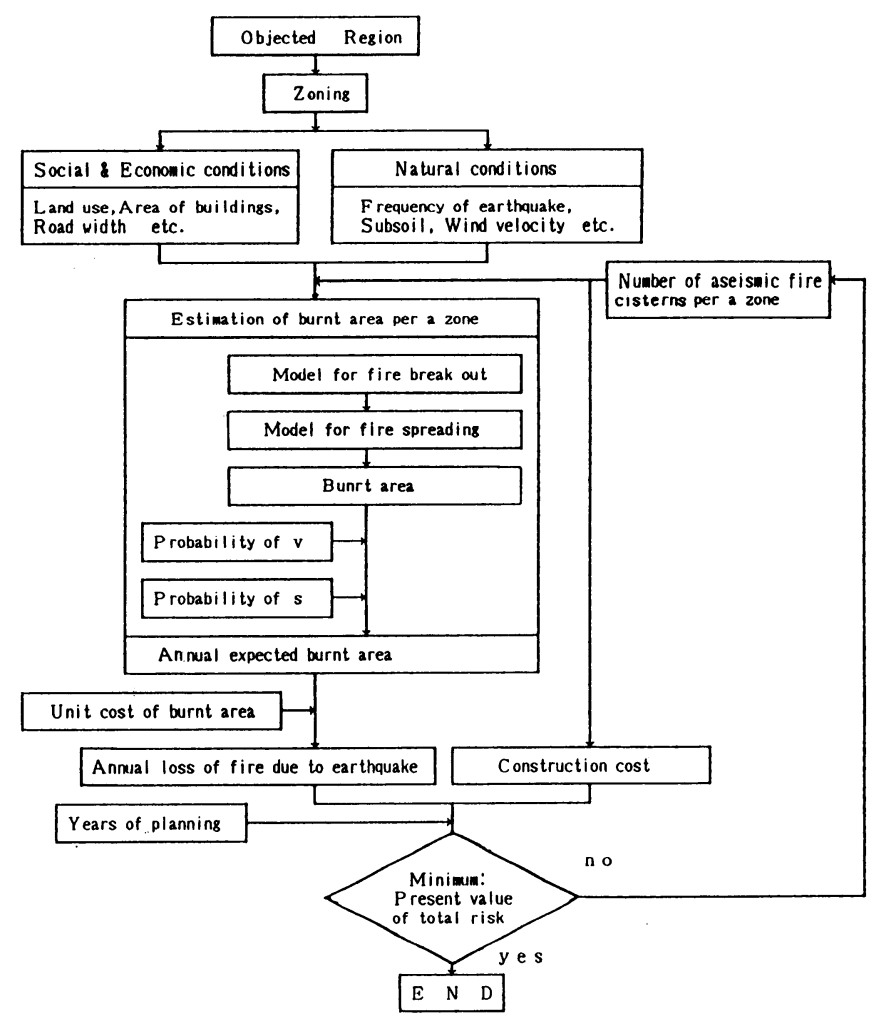

Fig. 3 The computation process.

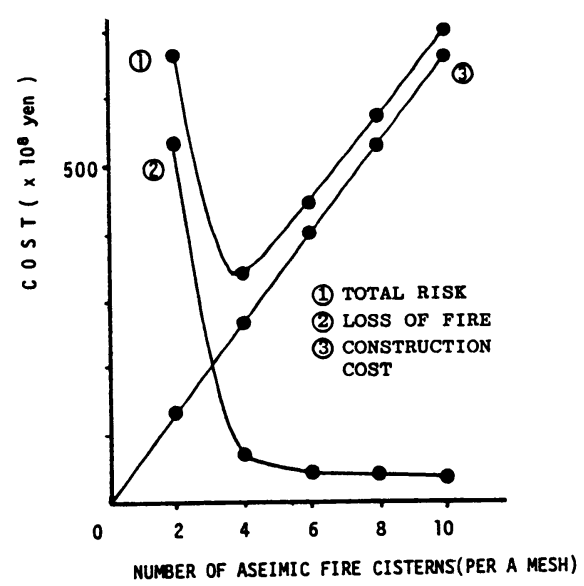

Fig. 4 The relationship between cost and number of aseismic fire cisterns (In this case, unit cost of burnt area is $¥ 200000$ and social discount ratio is $7 \%$.).
1) The optimal number of aseismic fire cisterns is little influenced by social discount ratio.

2) The evaluated monetary value of unit area of burnt-out floors does not affect linearly on the optimal number of aseismic fire cisterns.

\section{CONCLUDING REMARKS}

In planning and design of an engineering system where risks are potentially included, risk identification and its estimation are fundamentally important as well as risk evaluation. The present paper focusses on the seismic fire risk which potentially exists in urban area, and presents a method to plan the number of aseismic fire cisterns using Decision Theory.

Firstly, decision tree for aseismic fire cisterns planning is developed.

Secondly the annual seismic fire risk is formulated based on this decision tree, and finally location planning itself is formulated. In the previous works by Scawthorn et al. (1982), the role of land use pattern and fire-fighting activities to reduce the seismic fire risk was not clear. However the present paper formulate it in an explicit manner in the fire-spreading model and given conditions.

From the case study for Osaka city area, followings are concluded: 
1) Optimal number of aseismic fire cisterns is little affected by social discount ratio, and it does not incerase proportionally to the increase of monetary value of unit area of burnt-out floors.

2) Case study shows that four aseismic fire cisterns of $100 \mathrm{~m}^{3}$ capacity per 250 meters square are appropriate for Osaka city. This coincides with the standard introduced by Tokyo city (1979), which has been determind taking into account that the available area for one fire-engine is about $62000 \mathrm{~m}^{2}$ (this is approximately equal to the area of circle with radius $140 \mathrm{~m}$ ), and that about $40 \mathrm{~m}^{3}$ of water is used for usual fire-fightings. Taking this into consideration it can be said that rationality of the standard used by Tokyo city may be examined through same computation as is carried out in the case study for Osaka city.

In order to make these as fruitful conclusions further studies for the following problems remained for future should be made :

1) Sensitivity of the scale of zoning,

2) Interaction among unit zones,

3) Availability of fire-hydrants equipped to water supply pipelines after earthquake shocks of verious intensity.

4) The optimal number of fire cisterns depends on the characteristics of unit zone such as soil condition and land use. Thus, the model should be extended to determine the defferent number of fire cisterns at defferent zones taking into account of the interactions among zones.

\section{ACKNOWLEGEMENTS}

The authors express their gratitude to concerned offices of Osaka City and Tokyo City for their offering useful data, and special acknowlegement should be paid for Kinki University for the partial financial support.

\section{REFERENCES}

1) Ikeda, H. and Mizuno, T. : Reinforcement of fire cisterns and related problem, Heating, Air-conditioning and Sanitary Engineers of Japan, pp. 63-73, Vol.55, No.9, 1981 (in Japanese).

2) Kates, R. W. : Risk assessment of environment hazard, SCOPE Report No. 8, Int. Council of Scientific Unions, Scientific Committe on Problems of the Environment, Paris, 1976.

3) Matuo, M. and Horiuchi, T. : Earthquake damag and methodology of design of small diameter pipelines, Soils and Fundations, Vol. 19, No. 1, 1979.

4) Ang, A. H-S. and Tang, W. : Probability Concept in Engineering Planning and Design, Vol. 2, Decision, Risk, and Reliability, John Wiley \& Sons, Inc., 1984.

5) Mizuno, H. and Horiuchi, S. : Study on the estimation of fires in earthquakes, Trans. of AIJ, No. 250 , 1976 (in Japanese).

6) Scawthon, C. et al. : A model for urban post-earthquake fire hazard, Trans. of AIJ, No. 313, 1982 (in Jananese).

7) Suzuki, S. and Kinbara, T. : On fire spreading of a conflaglation, Applied Physics, Vol.9, No. 10, 1940 (in Japanese).

8) Study Team of Fire Prevention of Tokyo : Fire Spread Speed, 1942 (in Japanese).

9) Tosabayashi, T. : On Conflaglation of Muramatsu, Marine and Fire Insurance Association, of Japan, 1947 (in Japanese).

10) Hamada, M. : On fire spreading velocity in disaster, Sagami-shobo, 1954 (in Japanese).

11) Hisida, K. : Arithmetic of fire risk level, Marine and fire insurance association of Japan, 1954 (in Japanese).

12) Horiuti, S. : Study on Fire Prevention Facilities in Urban Area, Dissertation of Kyoto Univ., 1961 (in Japanese).

13) Yasuno, K. : Study of conflagration spread formula for wooden building, Bull. of JAFSE, Vol. 18, No. 2, 1968 (in Japanese).

14) Fujita, T. : Model for fire spread and simulation, Research of Disaster, Vol. 8, 1975 (in Japanese).

15) Sakai, K. : Study on Hamada's formula in view of burnt area and movement of fire spreading, City Planning Review, Vol. 18, 1983 (in Japanese).

16) Sasaki, H. : Road width and fire spread, Trans. of annual meeteng of AIJ, 1983 (in Japanese).

17) Yamashita, K. : Report of fire spreading conditions of Sakata conflagration ( I) - (V), Fire, Vol. 27, No.2 - No.6, 1977 (in Japanese).

18) Yasuno, K. et al. : A basic study on the fire spread of buildings, Bull. of JAFSE, Vol. 32 , No. 1, 1982 (in Japanese).

19) Yasuno, K. et al. : A basic study on fire spread formula of houses used by logistic curve, Trans. of AIJ, No. 311 , 1982 (in Japanese).

20) Yasuno, K. et al. : A basic study of fire spread formula (logistic curve) of wooden buildings by finite difference graphical 
method, Trans. of AIJ, No. 325, 1983 (in Japanese).

21) Yasuno, K. et al. : A basic strdy on effectiveness of suppressing building fire by water application, Bul. of JAFSE, Vol. 32 , No. 2, 1982 (in Japanese).

22) Namba, Y. : Study on mechanism of fire spread and its application to disaster prevention planning, Dissertaion of Kyoto Univ. , 1984 (in Japanese).

23) Japanese Association of Fire Science and Engineering : Fire Science Handbook, pp. 989 997, Rikashoin, 1950 (in Japanese).

24) Fire Defence Division of Fire-Defence Agency: Manual of Standard for Fire Fighting Actibity and Water Supply, Zenkoku-kajohourei, 1958 (in Japanese).

25) Comprehensive Planning Bureau of Osaka City : Mesh-data of Osaka City, Comprehensive Planning Bureau of Osaka City, 1976 (in Japanese).

26) Fire Department of Osaka City : Research of urban-ranking concerning with the fire prevention, Fire Department of Osaka City. 1981 (in Japanese).

27) Tokyo Fire Department : Countermeasure and administrative work of water supply for fire, Tokyo Joint Fire Prevention Society, 1978 (in Japanese). 